\title{
Diastolic function imaging: a comparison of real- time phase contrast magnetic resonance (CMR) imaging with segmented phase contrast CMR and Doppler echocardiography
}

\author{
Paaladinesh Thavendiranathan ${ }^{1,2^{*}}$, Jacob A Bender ${ }^{2}$, Jennifer Dickerson ${ }^{2}$, Michael Pennell ${ }^{2}$, Alice M Hinton², \\ Subha V Raman ${ }^{2}$, Orlando P Simonetti ${ }^{2}$
}

From 15th Annual SCMR Scientific Sessions

Orlando, FL, USA. 2-5 February 2012

\section{Background}

CMR measurement of mitral inflow velocities for the assessment of diastolic function is often infeasible in patients with dyspnea - patients who may benefit the most - due to their inability to breath-hold. Although real-time phase contrast (RT-PC) imaging may overcome this limitation, it has not been systematically evaluated. The objective of this study was to assess the accuracy of RT-PC for the measurement of mitral inflow velocities against segmented PC CMR and Doppler echocardiography.

\section{Methods}

37 healthy volunteers (aged $28 \pm 10$ years, 20 males) had echo and CMR studies within a week. Early (E) and late (A) mitral inflow velocities were measured by echo, segmented, and RT-PC CMR (Figure). The E and A velocities were obtained by averaging data from 2 heart beats by RT-PC and 3 heart beats by echo. RT-PC parameters were: $\mathrm{TR} / \mathrm{TE}=14.0 \mathrm{~ms} / 2.3 \mathrm{~ms}$, water excitation flip angle $=25 \circ, 10 \mathrm{~mm}$ slice, $90 \times 128$ matrix, EPI factor $=15$, TSENSE rate $=3$, and $V E N C=150 \mathrm{~cm} / \mathrm{s}$. Shared velocity encoding was used to achieve an effective temporal resolution of $28 \mathrm{~ms}$, but true temporal resolution was $56 \mathrm{~ms}$. Retro-gated segmented PC acquisition parameters: TR/TE $=4.5 / 1.9 \mathrm{~ms}, 10 \mathrm{~mm}$ slice, $100 \times 192$ matrix, TSENSE rate $=3, V E N C=150 \mathrm{~cm} / \mathrm{s}$, true temporal resolution $36 \mathrm{~ms}$. $E$ and $A$ velocities, and $E / A$ ratios between RT-PC and segmented PC CMR or Doppler

${ }^{1}$ Cardiovascular Medicine, Cleveland Clinic Foundation, Cleveland, $\mathrm{OH}$, USA Full list of author information is available at the end of the article echocardiography were compared using paired t-tests. Agreement between the techniques was assessed using concordance correlation coefficients and Bland-Altman analysis.

\section{Results}

Mean E velocities by echo, segmented, and RT-PC CMR were $75 \pm 15 \mathrm{~cm} / \mathrm{s}, 77 \pm 12 \mathrm{~cm} / \mathrm{s}$, and $73 \pm 12 \mathrm{~cm} / \mathrm{s}$, respectively. The RT-PC measurements were not different from echo $(\mathrm{p}=0.3)$, but were less than segmented $\mathrm{PC}$ $\operatorname{CMR}(\mathrm{p}=0.04)$. The A velocities $(38 \pm 12 \mathrm{~cm} / \mathrm{s}, 38 \pm 11$ $\mathrm{cm} / \mathrm{s}, 35 \pm 12 \mathrm{~cm} / \mathrm{s}$, respectively) were not different between RT-PC CMR and echo or segmented CMR ( $\mathrm{p}=0.3$ for both). There was also no difference in the $\mathrm{E} /$ A ratios $(2.2 \pm 0.6,2.2 \pm 0.7$, and $2.2 \pm 0.9$, respectively; $\mathrm{p}=0.6$ for both). There was moderate concordance between RT-PC CMR and segmented CMR and Echo for E, $\mathrm{A}$ and E/A ratio (Table 1). Although, the bias in measurement between RT-PC CMR and echo or segmented CMR was small, the LOA was wide.

\section{Conclusions}

We demonstrate for the first time the use of RT-PC imaging to measure mitral $\mathrm{E}$ and $\mathrm{A}$ velocities. There was modest agreement between RT-PC CMR and echo and segmented PC CMR. Further refinements of the RT-PC sequences are necessary; however, the use of RT-PC imaging provides an opportunity for wider application in patients who have difficulty with breath holding or arrhythmias. 


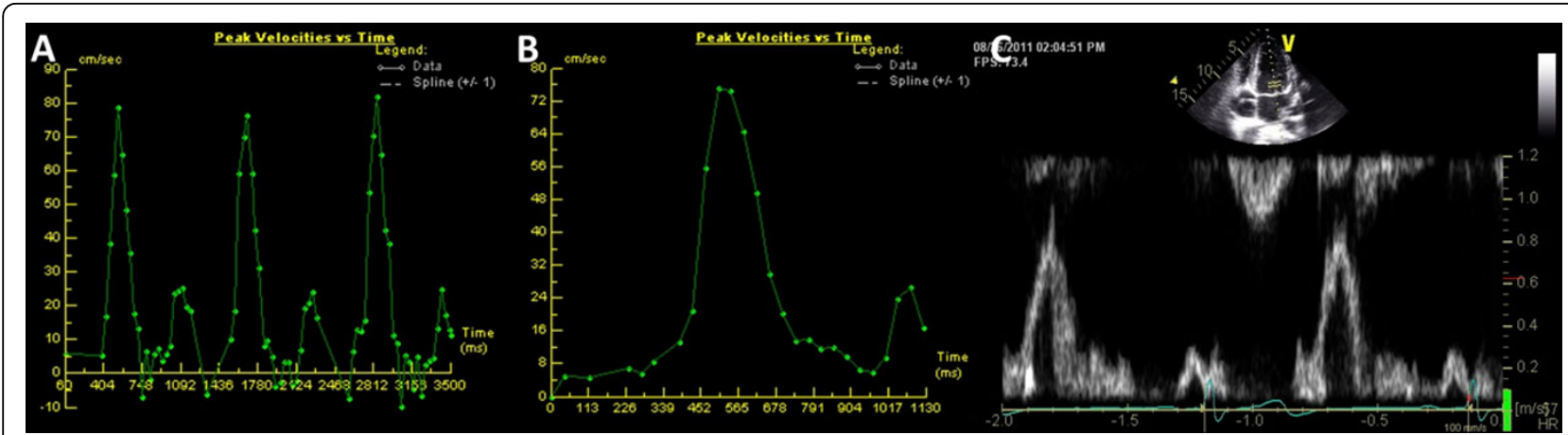

Figure 1 Mitral inflow velocities in one volunteer by all three techniques: (A) real-time phase contrast imaging (mean $E, A$, and $E / A$ were $78 \mathrm{~cm} /$ $\mathrm{s}, 25 \mathrm{~cm} / \mathrm{s}$, and 3.1), (B) segmented phase contrast imaging (mean $E, A$, and $E / A$ were $75 \mathrm{~cm} / \mathrm{s}, 27 \mathrm{~cm} / \mathrm{s}$, and 2.8 ), and (C) Doppler echocardiography (mean $\mathrm{E}, \mathrm{A}$, and $\mathrm{E} / \mathrm{A}$ were $77 \mathrm{~cm} / \mathrm{s}, 26 \mathrm{~cm} / \mathrm{s}$, and 3.0 ).

\section{Table 1}

\begin{tabular}{ccc}
\hline & Concordance Correlation & Bland-Altman Analysis (Bias \pm LOA)cm/s \\
\hline RT-PC CMR vs Echo E & 0.41 & $2.5 \pm 26.4$ \\
RT-PC CMR vs Echo A & 0.38 & $2.0 \pm 24.7$ \\
RT-PC CMR vs. Echo E/A ratio & 0.42 & $0.1 \pm 1.8$ \\
RT-PC CMR vs Segmented E & 0.56 & $3.9 \pm 21.4$ \\
RT-PC CMR vs Segmented A & 0.38 & $2.1 \pm 24.4$ \\
RT-PC CMR vs Segmented E/A & 0.42 & $-0.1 \pm 1.6$ \\
Segmented PC CMR vs echo E & 0.62 & $-1.4 \pm 17.3$ \\
Segmented PC CMR vs echo A & 0.72 & $-0.1 \pm 13.9$ \\
Segmented PC CMR vs echo E/A & 0.67 & $0.0 \pm 1.2$ \\
\hline
\end{tabular}

CMR, cardiac magnetic resonance imaging; RT-PC, Real-time phase contrast CMR; echo, echocardiography; LOA, level of agreement; 2SD, 2 standard deviations

\section{Funding}

National Institute of Health (NIH, R01).

\section{Author details}

${ }^{1}$ Cardiovascular Medicine, Cleveland Clinic Foundation, Cleveland, OH, USA.

${ }^{2}$ Cardiovascular Medicine, The Ohio State University, Columbus, OH, USA.

Published: 1 February 2012

doi:10.1186/1532-429X-14-S1-W21

Cite this article as: Thavendiranathan et al: Diastolic function imaging: a comparison of real-time phase contrast magnetic resonance (CMR) imaging with segmented phase contrast CMR and Doppler

echocardiography. Journal of Cardiovascular Magnetic Resonance 201214 (Suppl 1):W21.

\section{Submit your next manuscript to BioMed Central and take full advantage of:}

- Convenient online submission

- Thorough peer review

- No space constraints or color figure charges

- Immediate publication on acceptance

- Inclusion in PubMed, CAS, Scopus and Google Scholar

- Research which is freely available for redistribution 